\title{
GISÈLE PINEAU, Ady, soleil noir
}

\section{Alba Pessini}

\section{OpenEdition \\ Journals}

\section{Édition électronique}

URL : https://journals.openedition.org/studifrancesi/45594

DOI : 10.4000/studifrancesi.45594

ISSN : 2421-5856

\section{Éditeur}

Rosenberg \& Sellier

\section{Édition imprimée}

Date de publication : 1 août 2021

Pagination : 418-419

ISSN : 0039-2944

\section{Référence électronique}

Alba Pessini, « GISĖLE PINEAU, Ady, soleil noir », Studi Francesi [En ligne], 194 (LXV | II) | 2021, mis en ligne le 01 septembre 2021, consulté le 15 octobre 2022. URL : http://journals.openedition.org/studifrancesi/ 45594 ; DOI : https://doi.org/10.4000/studifrancesi.45594

Ce document a été généré automatiquement le 15 octobre 2022.

\section{(c) (†)}

Creative Commons - Attribution - Pas d'Utilisation Commerciale - Pas de Modification 4.0 International - CC BY-NC-ND 4.0

https://creativecommons.org/licenses/by-nc-nd/4.0/ 


\title{
GISÈLE PINEAU, Ady, soleil noir
}

\author{
Alba Pessini
}

\section{RÉFÉRENCE}

GISÈLE PINEAU, Ady, soleil noir, Paris, Philippe Rey, 2021, 301 pp.

1 Gisèle Pineau signe avec Ady, soleil noir son treizième roman (sans compter les ouvrages pour la jeunesse) et convie ses lecteurs dans le tourbillon du Paris des années trente où nait, se fortifie et se conclut, sous les coups menaçants de la deuxième guerre mondiale, l'histoire d'amour entre Man Ray (né Emmanuel Radnitsky) le grand artiste, peintre et photographe et Adrienne Fidelin (Ady), jeune guadeloupéenne qui deviendra une de ses muses et sa maîtresse pendant cinq ans. C'est cette dernière qui, en ouverture du roman à l'âge de soixante-quinze ans, nous entraîne dans ses souvenirs, ouvre les tiroirs d'une mémoire qui reconstruit ces années de bonheur intensément vécu.

2 L'auteur orchestre la narration en s'attachant à des lieux et à des dates qui servent d'intitulés aux différents chapitres. Tout d'abord les lieux, il s'agit bien évidemment de Paris, Paname, comme la narratrice la nomme à plusieurs reprises au cours de son évocation. Ady y débarque à l'âge de 15 ans de sa Guadeloupe natale, rescapée avec ses trois sœurs et son frère d'un cyclone ravageur qui les a privés de leur mère, Mathilde, qui a succombé sous les gravats de leur maison et la déroute de leur père, Maxime, qui n'a pas survécu à la perte douloureuse de sa femme et s'est laissé mourir lentement de chagrin. Le premier chapitre nous transporte au 33, rue Blomet, l'adresse du célèbre Bal Blomet, ex Bal Nègre, où Ady donne libre cours à sa passion, la danse, qu'elle cultive depuis son enfance, encouragée par sa mère, «Mathilde rit et dit que j'ai du feu dans le corps. Déjà je danse sur toutes les musiques. Je lève la jambe. Je fais le grand écart. Je remue les reins et les épaules [...]» (p. 40). À Paris, elle en fait son gagne-pain subvenant ainsi à ses menus plaisirs sous le regard réprobateur de sa grande sœur Raymonde: «En 1934, j'appartiens à une troupe qui se produit dans les cabarets et les guinguettes au bord de la Seine. Je danse habillée en doudou. Je danse la biguine, le quadrille, la mazurka. Je n'ai pas besoin de rhum pour m'enivrer. Me suffit de danser pour éloigner 
les ténèbres» (p. 40). C'est surtout sur la piste du bal de la rue Blomet qu'Ady combat ses démons, tente d'évacuer des images qui la hantent, c'est là également qu'adviendra sa toute première rencontre avec Man Ray, l'homme qui va remplir ses jours et ses nuits cinq années durant.

3 Le deuxième chapitre daté 1928 retrace l'année tragique du cyclone ainsi que l'évocation de la vie de la famille Fidelin qui précède le départ et la traversée qui conduira les sœurs et le jeune frère en métropole sous la protection de Raymonde, l'aînée, qui y vit déjà avec son mari et ses enfants depuis quelques années. C'est avec le troisième chapitre qui porte comme titre l'adresse de l'atelier de l'artiste, «31 rue Campagne-Première» que la narratrice entre dans le vif de sa rencontre avec Man Ray. Gisèle Pineau laisse la parole à Ady pour qu'elle évoque l'artiste qui a marqué l'histoire de la photographie en ce début de $\mathrm{xx}^{\mathrm{e}}$ siècle, celui qui vit passer à cette adresse toutes les grandes figures intellectuelles et artistiques de l'époque. Mais elle nous détaille surtout l'homme qui a partagé celles qui resteront les plus belles années de sa vie scandées par trois mots «joie, jouer, jouir» (attribués par Marcel Duchamp à Man Ray) qu'Ady n'a de cesse de répéter, tout au long de son récit, comme une sorte de devise qu'elle nous illustre plus longuement dans le quatrième chapitre intitulé «Vingt et un ans/quarante-six ans»: «Joie. Oui, je ris beaucoup, Je ris aux éclats. Il est drôle et facile à vivre, mon petit Man» (p. 151). «Jouer. Partout où nous allons, il a son appareil photo. [...] Muni de cet attirail, il se métamorphose en grand sorcier, en magicien, en maître des lumières... il jubile alors» (p. 153). «Jouir. Oui nous faisons l'amour. Jouir nous enivre et nous fait basculer dans le vide. [...] Jouir nous rend plus vivants. Jouir nous console des horreurs du monde» (p. 154).

4 Ady plonge le lecteur dans les lieux et les milieux fréquentés par les surréalistes, dans cette vie de bohème et de liberté totale qu'elle partage, à Montparnasse et à Mougins l'été, avec les amis du photographe américain: Marcel Duchamp, Paul Éluard et sa femme Nusch, Pablo Picasso et Dora Maar, Lee Miller et Roland Penrose. Paris est également le point de chute d'Antillais et de Guyanais à la recherche d'une vie meilleure qui vont peupler les ateliers de l'usine Renault de Boulogne-Billancourt: «métallos, ajusteurs, soudeurs. [...] Ils logent dans des foyers de travailleurs sous les toits d'immeubles ou d'hôtels, dans de miséreuses chambrettes [...]» (p. 19). D'autres seront les protagonistes - avec des intellectuels noirs provenant d'Afrique, d'Amérique et de Haïti - d'une saison qui donnera naissance à la Négritude qu'Ady n'a que côtoyée de loin: «On raconte qu'ils s'enfoncent avec suffisance dans les fauteuils de velours des sœurs Nardal, [...] papotent à n'en plus finir: colonisation, esclavage, apartheid, négritude, ségrégation, décolonisation, [...] identité, conscience noire... Tout y passe!» (p. 24). Ce sont des années inoubliables, d'une effervescence sans pareil dont la jeune Ady s'imprègne et qu'elle vit pleinement auprès de «son petit Man» parce que ce qui l'intéresse n'est pas vraiment ce qui s'y joue du point de vue culturel et intellectuel mais la relation unique et intense qui s'est créée.

5 Malgré les années qui avancent et qui conduisent irréversiblement vers le désastre, vers un autre cyclone, celui de la guerre, le couple tente de se préserver des secousses qui font trembler l'Europe; Man, artiste déjà amplement reconnu, sillonne le continent, Ady, la plupart du temps, l'attend dans leur appartement de la rue Denfert Rochereau où elle prend soin de leur nid. Le septième et dernier chapitre "1940 et après...» convoque les derniers mois de leur vie commune, le reste de l'existence d'Ady. Gisèle Pineau n'y consacre que quelques pages, ces cinq années valent une vie entière semble 
nous dire l'auteure qui a voulu mettre en évidence le caractère exceptionnel, extravagant et unique de la parabole existentielle de cette jeune guadeloupéenne qui a partagé la vie d'un des plus grands artistes du $\mathrm{xx}^{\mathrm{e}}$ siècle.

6 Gisèle Pineau nous livre le portrait attachant d'une jeune femme qui s'ouvre à la vie, prête à toute expérience sans aucun préjugé; grâce aux nombreuses recherches de l'auteure, notamment dans la famille d'André, le mari d'Adrienne (entretien du 2 janvier 2021 Franceinfo, Le portail des Outre-mer), les passionnés de cette période ajoutent un nom à un visage inconnu qui fait partie d'une photo célèbre de la période surréaliste (p. 66), lors d'un déjeuner sur l'herbe. Le "petit soleil noir» de Man Ray que Pineau ressuscite, éclaire le lecteur de sa gaité, de sa passion et de sa fougue. 